\title{
Incidence and risk factors of congenital heart disease in Qingdao: a prospective cohort study
}

\author{
Xiao Jin ${ }^{1 \dagger}$, Wei $\mathrm{Ni}^{2 \dagger}$, Guolan Wang ${ }^{2}$, Qin Wu², Jun Zhang ${ }^{2}$, Guoju Li ${ }^{2}$, Na Jiao ${ }^{2}$, Wenjing Chen ${ }^{3}$, Qing Liu ${ }^{3}$, \\ $\mathrm{Li} \mathrm{GaO}^{3}$ and Quansheng Xing ${ }^{2^{*}}$
}

\begin{abstract}
Background: Many studies have been conducted to assess the incidence of congenital heart disease (CHD). However, results were greatly inconsistent among these studies with a broad range of findings.

Methods: A prospective census-based cohort study was conducted in Qingdao, China, from August 1, 2018 to April 30, 2019. All of the local registered pregnant women were continuously investigated and followed from 15 to 20 weeks of gestation to delivery, tracking the CHD cases in both the fetal and neonatal stages. A logistic regression model was applied to assess the association between CHD and possible risk factors.

Results: The positive rate of prenatal CHD screening was 14.36 per 1000 fetuses and the incidence of CHD was 9.38 per 1000 live births. Results from logistic regression indicated that, living in the countryside (odds ratio, (OR): 0.771; 95\% confidence interval, (Cl): 0.628-0.946) and having a childbearing history (OR: 0.802; 95\%Cl: 0.676-0.951) were negatively associated with CHD. However, twin pregnancy (OR: 1.957, 95\% Cl: 1.245-3.076), illness in the first trimester (OR: 1.306; 95\% Cl: 1.048-1.628), a family history of CHD (OR: 7.156; 95\% Cl: 3.293-15.552), and having a child with a birth defect (OR: 2.086; 95\% Cl: 1.167-3.731) were positively associated with CHD.

Conclusion: CHD is a serious health problem in Qingdao. The CHD incidence found in this study was similar to existing research. The positive rate of prenatal CHD screening was higher than the incidence of neonatal CHD. Moreover, CHD risk factors were identified in our study, and our findings may have great implications for formation CHD intervention strategies.
\end{abstract}

Keywords: Epidemiologic studies, Congenital heart defects, Incidence, Regression analysis, Risk factors

\section{Introduction}

Congenital heart disease (CHD) is typically defined as a structural abnormality of the heart and/or great vessels during the embryonic period, also known as congenital heart malformation. During the embryonic development period (especially within the first 2-3 months of

\footnotetext{
* Correspondence: xingqs0532@163.com

${ }^{+}$Xiao Jin and Wei Ni contributed equally to this work.

${ }^{2}$ Qingdao Women and Children's Hospital, Qingdao University, Qingdao, Shandong Province, No.6 Tongfu Road, Qingdao 266000, China

Full list of author information is available at the end of the article
}

pregnancy), local anatomical structure abnormalities caused by the formation of the heart and large blood vessels occur, or there is a failure to close the channels that should be automatically closed after birth (normal in the fetus). This is referred to as CHD [1]. The categories of severity of CHD are as follows: severe CHD includes all those with cyanotic heart disease (d-transposition of the great arteries, tetralogy of fallot, including pulmonary atresia and absent pulmonary valve, hypoplastic right heart, hypoplastic left heart, single ventricle, double outlet right ventricle, truncus arteriosus, total

(C) The Author(s). 2021 Open Access This article is licensed under a Creative Commons Attribution 4.0 International License, which permits use, sharing, adaptation, distribution and reproduction in any medium or format, as long as you give appropriate credit to the original author(s) and the source, provide a link to the Creative Commons licence, and indicate if changes were made. The images or other third party material in this article are included in the article's Creative Commons licence, unless indicated otherwise in a credit line to the material. If material is not included in the article's Creative Commons licence and your intended use is not permitted by statutory regulation or exceeds the permitted use, you will need to obtain permission directly from the copyright holder. To view a copy of this licence, visit http://creativecommons.org/licenses/by/4.0/ The Creative Commons Public Domain Dedication waiver (http://creativecommons.org/publicdomain/zero/1.0/) applies to the data made available in this article, unless otherwise stated in a credit line to the data. 
anomalous pulmonary venous connection, and critical pulmonic stenosis) and acyanotic lesions (atrioventricular septal defect, large ventricular septal defect, large patent ductus arteriosus, critical or severe aortic stenosis, severe pulmonic stenosis, and critical coarc); moderate CHD includes mild or moderate aortic stenosis or aortic incompetence, moderate pulmonic stenosis or incompetence, noncritical coarc, large atrial septal defect, and complex forms of ventricular septal defects; and mild CHD includes small ventricular septal defect, small patent ductus arteriosus, mild pulmonic stenosis, bicuspid aortic valve without aortic stenosis or aortic incompetence, and small or spontaneously closed atrial septal defects [2]. Since the beginning of the twenty-first century, CHD has been the most frequent form of congenital anomaly found in newborn infants around the globe, accounting for one-third of all anomalies with high mortality [3]. An updated systematic review and meta-analysis of 260 studies revealed that between 1970 and 2017, the prevalence of CHD globally increased by $10 \%$ every 5 years [4].

To date, many studies have been conducted to assess the prevalence of CHD and its associated factors. However, results were greatly inconsistent among these studies with a range from $4 / 1000$ to $50 / 1000$ [2]. In North America, a prevalence of 6.9 per 1000 live births (95\% CI: 6.7-7.1) was reported in CHD cases [3]. In China, CHD was identified in 1103 neonates, with an updated overall prevalence of 8.98 per 1000 in 18 hospitals, including the eastern and western regions [5]. However, recently researchers described the prevalence of circulatory system malformations as $3.6 / 1000$ births, based on a prefecture-wide hospital-based birth cohort at the beginning of 12 weeks gestation in Japan [6]. Genetic and environmental factors are the two most important factors affecting the risk of CHD [7, 8]. It was considered that the difference of $\mathrm{CHD}$ incidence in different areas may be attributed to geographical, demographic, and socio-economic variations [9]. Strikingly, an increasing body of data has revealed the different incidences of $\mathrm{CHD}$ in different areas. We think that this phenomenon might be related to study methods in addition to genetic and environmental factors, because bias in the sampling monitor could result in inaccurate data. Qingdao is situated in eastern China, and has a mid-temperate continental monsoon climate with an annual average temperature of $12.7^{\circ} \mathrm{C}$. In our study, we aimed to identify the incidence and risk factors of CHD in Qingdao. We conducted a municipal census and prospective cohort study, involving all of the pregnant women in Qingdao.

\section{Methods}

\section{Study design and data collection}

A birth cohort was conducted enrolling 64,763 registered pregnant women at 15-20 weeks of gestation from August 1, 2018 to April 30, 2019, on the overall citywide level. This study was carried out by the Qingdao Municipal Center for Birth Defect Control and Prevention (QMCBDCP) and Qingdao Women and Children's Hospital (QWCH). All of the registered pregnant women were continuously followed from the fetal stage to the neonatal stage to track CHD cases. The data collection tool was developed according to the following steps. First, we designed a questionnaire by consulting the literature to investigate the characteristics of pregnant women and their partners, such as demographic information, pregnancy information, health status and other potential risk factors such as maternal dietary intake during pregnancy. Next, the questionnaires were sent to prenatal screening hospitals throughout the city and filled out by all of the pregnant women getting the Down's screening at 15-20 weeks of gestation. In this study, we focused on CHD from the fetal stage to the neonatal stage. Two screenings for CHD were performed on enrolled pregnant women. One was performed on fetuses during 20-28 weeks of gestation, and another was performed on newborns at birth. If the fetus was prenatally screened with fetal CHD, the family would be informed about the condition and provided with medical counseling by a multidisciplinary team in QMCBDCP and QWCH. The prenatal cases of CHD reconfirmed the diagnosis again before discharge in the neonatal stage. For each pregnant woman, we continuously the followed results of these two screenings as well as the pregnancy outcomes, which were obtained by telephone follow-up to enrolled pregnant women and electronic medical records in medical institutions. In order to ensure that all targeted pregnant women were enrolled, our study included all relevant institutions such as prenatal screening and delivery hospitals in the maternal and child health management network. For the accuracy of information and in order to minimize bias among hospitals, investigators, and echocardiographers, we conducted systematic training for the staff committed to the survey as well as routine sampling checks. In addition, the identity card numbers of enrolled pregnant women were used as the unique identification code linking the information through continuous stages.

\section{Definitions}

In our study, we identified all of the CHD cases, including fetuses and newborns based on whether there was a structural abnormality of the heart and/or great vessels. All types of CHD were coded according to ICD-11. All fetal $\mathrm{CHD}$ cases were screened by fetal ultrasound scan, 
and neonatal CHD cases were screened and diagnosed by pulse oximetry screening, clinical observation, physical examination, echocardiography, cardiac catheterization and magnetic resonance angiography (MRA) as needed [10-13]. A fractional (as opposed to functional) oxygen saturation of $\geq 94 \%$ was accepted as normal [14-16]. The positive rate of prenatal CHD screening was calculated as the total number of fetal heart structure abnormalities in the cohort divided by sum of fetuses screened in the same period. The incidence rate in newborns was calculated as the total number of neonatal CHD in the cohort divided by the sum of neonates in the same period. The false negative rate was equal to the number of false negatives divided by the sum of true positives and false negatives. In our study, pre-pregnancy body mass index (BMI) was categorized according to the World Health Organization adult criteria. $\mathrm{BMI}<18.5 \mathrm{~kg} / \mathrm{m}^{2}$ was considered lean, BMI between 18.5 and $24.9 \mathrm{~kg} / \mathrm{m}^{2}$ was considered healthy, and $\mathrm{BMI} \geq 25 \mathrm{~kg} / \mathrm{m}^{2}$ was considered overweight or obese. Education levels were categorized as low (received no education, primary school, or secondary school), medium (high school or college/university), and high (postgraduate or above). We collected information on dietary patterns (a well-balanced diet (including both vegetables and meat, a diet with less vegetables, and a diet with less meat) of pregnant women before pregnancy. The history of illness in first trimester, which included hypertension, diabetes, anemia, cold, fever, thyroid disease, rubella virus infection, hepatitis B, genitourinary system diseases and immune system diseases was recorded and reflected the health status of the pregnant women. A history of having a child with birth defects meant that the pregnant woman gave birth to one or more children with birth defects before this pregnancy. A family history of birth defects referred to birth defects of immediate relatives of the couple. A family history of CHD referred to CHD of immediate relatives of the couple. Husband smoking before pregnancy was categorized at four levels: does not smoke, smokes less than 10 cigarettes a day, smokes between 10 and 20 cigarettes a day, and smokes more than 20 cigarettes a day. Atrial septal defects within oval fossa (sinus venosus defects, interatrial communication through the coronary sinus orifice and other specified congenital anomalies of atrial septum were not included), patent foramen ovale, and patent ductus arteriosus among fetuses and neonates $<28$ days of life were excluded because they are normal fetal and neonatal findings.

This study was approved by the Ethics Commission of Qingdao Women and Children's Hospital (QFFLL-KY2020-11) and written informed consent was obtained from involved patients prior to enrollment. To minimize bias among hospitals, investigators and echocardiographers, we provided systematic training for the staff committed to the survey.

\section{Data statistical analysis}

In order to detect the independent factors of $\mathrm{CHD}$, univariate and multivariable analyses were performed. Chisquare test were first conducted with a total of 16 factors between the CHD and no CHD groups. All of the factors are listed in Table 1, revealing their distribution. Univariate logistic regression analysis also was performed. A multivariable regression model was then performed with significant factors selected by univariate analysis to tease out the independent factors for CHD. The association between independent factors and CHD was quantified by odds ratio (OR). Meanwhile, model selection was performed by excluding some uncertain data or changing the definition of a major variable of interest or outcome.

A $p$ value less than 0.05 (two-tailed) was considered statistically significant. The missing data for each factor was removed for both univariate and multivariable analysis, and the rate of missing data ranged from 0 to $16.5 \%$. Analyses were performed using SPSS software version 22.0.

\section{Results \\ Data characteristics}

A total of 64,763 pregnant women were enrolled in the cohort and followed up from 15 to 20 weeks of gestation to birth. The follow-up time was approximately 9-29 weeks.

Among all the pregnant women, we were able to identify $805(1.24 \%)$ pregnancies that ended with termination of pregnancy, abortion, or stillbirth, 63,958 (98.76\%) pregnancies in which newborns were delivered, and 348 $(0.54 \%)$ pregnancies in which the outcome could not be tracked due to failure to follow-up. As shown in Fig. 1, 268 pregnancies were terminated before the first stage of prenatal screening, and $926 \mathrm{CHD}$ cases were screened in the fetal stage, with a positive rate of prenatal CHD screening of 14.36 per 1000 fetuses $(926 / 64,495)$. Other than cases that ended in termination, abortion, 794 fetal cases of CHD were delivered. Among these births, 433 were screened and diagnosed with neonatal CHD in the neonatal stage, 317 were screened but not diagnosed with neonatal CHD, and 44 were not screened and failed to follow up. Among the 63,164 newborns that were screened but not diagnosed with CHD in the fetal stage, 37 of them were screened with neonatal CHD after delivery. Overall, CHD incidence was 9.38 per 1000 live births $(602 / 64,147)$. The false negative rate was $6.15 \%$ (37/602).

In our study, all of the CHD cases, including fetuses and newborns, were classified into 30 categories according to ICD-11. As shown in Table 2, the predominant 
Table 1 Characteristics and distribution for risk factors between CHD and no CHD group ${ }^{a}$

\begin{tabular}{|c|c|c|c|c|c|}
\hline Risk factors & Total & CHD n (\%) & No CHD n (\%) & $x^{2}$ value & $P$ value \\
\hline \multicolumn{6}{|l|}{ Twin pregnancy } \\
\hline No & 63,590 & $582(0.92 \%)$ & $63,008(99.08 \%)$ & 7.801 & 0.005 \\
\hline Yes & 1173 & $20(1.71 \%)$ & 1153(98.29\%) & & \\
\hline \multicolumn{6}{|l|}{ Maternal age (years) } \\
\hline$<35$ & 51,651 & $484(0.94 \%)$ & $51,167(99.06 \%)$ & 1.560 & 0.692 \\
\hline$\geq 35$ & 13,112 & $118(0.90 \%)$ & 12,994(99.10\%) & & \\
\hline \multicolumn{6}{|l|}{$\mathrm{BMI}\left(\mathrm{kg} / \mathrm{m}^{2}\right)$} \\
\hline$<18.5$ & 5269 & $61(1.16 \%)$ & $5208(98.84 \%)$ & -1.162 & 0.245 \\
\hline $18.5-24.9$ & 37,202 & $361(0.97 \%)$ & $36,841(99.03 \%)$ & & \\
\hline$\geq 25$ & 11,603 & $108(0.93 \%)$ & $11,495(99.07 \%)$ & & \\
\hline \multicolumn{6}{|l|}{ Living location } \\
\hline City & 40,274 & $424(1.05 \%)$ & $39,850(98.95 \%)$ & 8.334 & 0.004 \\
\hline Countryside & 15,324 & $120(0.78 \%)$ & $15,204(99.22 \%)$ & & \\
\hline \multicolumn{6}{|l|}{ Assisted reproduction } \\
\hline No & 54,827 & $531(0.97 \%)$ & $54,296(99.03 \%)$ & 3.704 & 0.054 \\
\hline Yes & 789 & $13(1.65 \%)$ & $776(97.25 \%)$ & & \\
\hline \multicolumn{6}{|c|}{ Maternal educational level } \\
\hline Low & 11,957 & $92(0.77 \%)$ & $11,865(99.23 \%)$ & -3.274 & 0.001 \\
\hline Medium & 40,605 & $409(1.01 \%)$ & $40,196(98.99 \%)$ & & \\
\hline High & 3043 & $43(1.41 \%)$ & $3000(98.59 \%)$ & & \\
\hline \multicolumn{6}{|l|}{ Dietary patterns } \\
\hline Well-balanced diet & 47,409 & $465(0.98 \%)$ & $46,944(99.02 \%)$ & -0.114 & 0.909 \\
\hline Eat less meat & 6440 & $61(0.95 \%)$ & 6379(99.05\%) & & \\
\hline Eat less vegetables & 1747 & 18(1.03\%) & 1729(98.07\%) & & \\
\hline \multicolumn{6}{|l|}{ Husband age (years) } \\
\hline$<35$ & 38,489 & $395(1.03 \%)$ & $38,095(98.97 \%)$ & 2.892 & 0.089 \\
\hline$\geq 35$ & 17,081 & $149(0.87 \%)$ & $16,932(99.13 \%)$ & & \\
\hline \multicolumn{6}{|c|}{ Number of previous pregnancies } \\
\hline 0 & 17,500 & 189(1.08\%) & $17,311(98.92 \%)$ & -2.215 & 0.027 \\
\hline 1 & 20,106 & $201(1.00 \%)$ & $19,905(99.00 \%)$ & & \\
\hline$>1$ & 18,013 & $153(0.85 \%)$ & $17,860(99.15 \%)$ & & \\
\hline \multicolumn{6}{|l|}{ Fertility history } \\
\hline 0 & 26,021 & $288(1.11 \%)$ & $25,733(98.89 \%)$ & 8.615 & 0.003 \\
\hline$\geq 1$ & 29,598 & $255(0.86 \%)$ & $29,343(99.14 \%)$ & & \\
\hline \multicolumn{6}{|c|}{ History of having a child with birth defects } \\
\hline No & 55,015 & $531(0.97 \%)$ & $54,484(99.03 \%)$ & 6.449 & 0.011 \\
\hline Yes & 604 & 12(1.99\%) & $592(98.01 \%)$ & & \\
\hline \multicolumn{6}{|c|}{ History of illness in the first trimester } \\
\hline No & 47,776 & $446(0.93 \%)$ & $47,330(99.07 \%)$ & 6.940 & 0.008 \\
\hline Yes & 7844 & $98(1.25 \%)$ & 7746(98.75\%) & & \\
\hline \multicolumn{6}{|c|}{ Family history of birth defect } \\
\hline No & 55,222 & $534(0.97 \%)$ & $54,688(99.03 \%)$ & 9.746 & 0.002 \\
\hline Yes & 398 & $10(2.51 \%)$ & $388(97.49 \%)$ & & \\
\hline
\end{tabular}


Table 1 Characteristics and distribution for risk factors between CHD and no CHD group ${ }^{\mathrm{a}}$ (Continued)

\begin{tabular}{|c|c|c|c|c|c|}
\hline Risk factors & Total & CHD n (\%) & No CHD n (\%) & $x^{2}$ value & $P$ value \\
\hline \multicolumn{6}{|l|}{ Family history of CHD } \\
\hline No & 55,521 & $537(0.97 \%)$ & $54,984(99.03 \%)$ & 38.012 & $<0.001$ \\
\hline Yes & 99 & $7(7.07 \%)$ & $92(92.93 \%)$ & & \\
\hline \multicolumn{6}{|l|}{ History of folic acid intake } \\
\hline Does not eat folic acid & 3423 & $21(0.61 \%)$ & $3402(99.39 \%)$ & -2.279 & 0.022 \\
\hline Eating folic acid 3 months before after pregnancy & 37,683 & $364(0.97 \%)$ & $37,319(99.03 \%)$ & & \\
\hline Eating folic acid 6 months before and after Pregnancy & 14,514 & $159(1.10 \%)$ & $14,355(98.90 \%)$ & & \\
\hline \multicolumn{6}{|l|}{ History of husband smoking (cigarettes) } \\
\hline 0 & 34,101 & $355(1.04 \%)$ & $33,746(98.96 \%)$ & -1.641 & 0.101 \\
\hline$<10$ & 10,674 & $87(0.82 \%)$ & $10,587(99.18 \%)$ & & \\
\hline 10-19 & 7059 & 68(0.96\%) & $6991(99.04 \%)$ & & \\
\hline$\geq 20$ & 3786 & $34(0.90 \%)$ & $3752(99.10 \%)$ & & \\
\hline
\end{tabular}

${ }^{\mathrm{a}}$ For each factor, except for counts of its levels listed in the table, the rest was the count of missing data

types of $\mathrm{CHD}$ in the fetal stage were congenital tricuspid regurgitation (31.64\%), ventricular septal defect $(31.10 \%)$, vascular ring $(8.53 \%)$, and congenital pulmonary regurgitation $(5.72 \%)$. In the neonatal stage, the predominant types of CHD were ventricular septal defect $(42.13 \%)$, congenital tricuspid regurgitation (19.36\%), vascular ring $(16.81 \%)$, and congenital pulmonary regurgitation (4.89\%). The main types and incidence of CHD screened and diagnosed are depicted in Fig. 2. As shown in Table 3, the types of CHD without abnormalities after delivery mainly included congenital tricuspid regurgitation (62.78\%), ventricular septal defect (23.03\%), and congenital pulmonary regurgitation $(9.46 \%)$ in prenatal screening. In the newborn screening stage, the types of missed CHD mainly included ventricular septal defect (54.05\%), vascular ring (13.51\%), congenital tricuspid regurgitation (5.41\%), and atrial septal defect (5.41\%).

\section{Factors associated with CHD}

The results of univariate logistic regression analysis are show in Fig. 3. Twin pregnancy, educational level of pregnant women, living location, fertility history, the number of previous pregnancies, history of illness in the first trimester of pregnancy, history of having a child

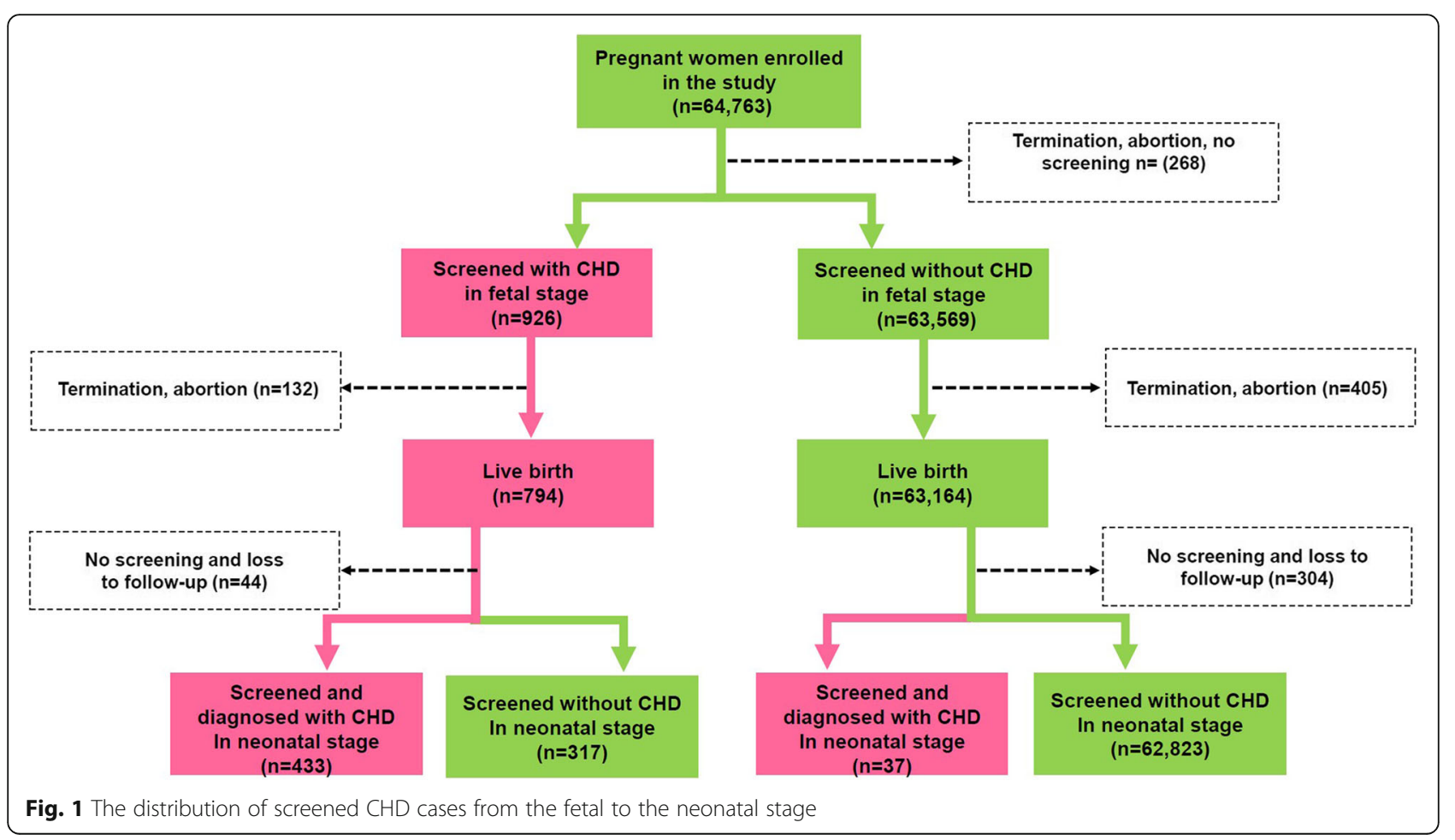


Table 2 Proportion of different types of CHD in both of the fetal and neonatal stage according to ICD-11

\begin{tabular}{|c|c|c|c|c|}
\hline Congenital heart disease & ICD-11 code & Fetus n (\%) & Termination $\mathrm{n}(\%)$ & Newborns $\mathrm{n}(\%)$ \\
\hline Transposition of the great arteries & LA85.1 & $7(0.76 \%)$ & $7(5.30 \%)$ & $0(0.00 \%)$ \\
\hline Double outlet right ventricle & LA85.2 & $4(0.43 \%)$ & $3(2.27 \%)$ & $1(0.21 \%)$ \\
\hline Common arterial trunk & LA85.4 & $1(0.11 \%)$ & $0(0.00 \%)$ & $2(0.43 \%)$ \\
\hline Partial anomalous pulmonary venous connection & LA86.21 & $1(0.11 \%)$ & $2(1.52 \%)$ & $1(0.21 \%)$ \\
\hline Congenital tricuspid regurgitation & LA87.00 & 293(31.64\%) & $5(3.79 \%)$ & $91(19.36 \%)$ \\
\hline Ebstein malformation of tricuspid valve & LA87.0Y & $1(0.11 \%)$ & $1(0.76 \%)$ & $0(0.00 \%)$ \\
\hline Congenital mitral regurgitation & LA87.10 & $7(0.76 \%)$ & $0(0.00 \%)$ & $2(0.43 \%)$ \\
\hline Atrioventricular septal defect & LA87.20 & $11(1.19 \%)$ & $9(6.82 \%)$ & $2(0.43 \%)$ \\
\hline Tetralogy of Fallot & LA88.2 & 29(3.13\%) & $20(15.15 \%)$ & $10(2.13 \%)$ \\
\hline Ventricular septal defect & LA88.4 & 288(31.10\%) & $15(11.36 \%)$ & 198(42.13\%) \\
\hline Hypoplastic right heart syndrome & LA88.Y & $5(0.54 \%)$ & $4(3.03 \%)$ & $1(0.21 \%)$ \\
\hline Hypoplastic left heart syndrome & LA89.3 & $3(0.32 \%)$ & $3(2.27 \%)$ & $1(0.21 \%)$ \\
\hline Functionally univentricular heart & LA89 & $6(0.65 \%)$ & $6(4.55 \%)$ & $0(0.00 \%)$ \\
\hline Congenital pulmonary valvar stenosis & LA8A.00 & $27(2.92 \%)$ & $3(2.27 \%)$ & 19(4.04\%) \\
\hline Congenital pulmonary regurgitation & LA8A.01 & $53(5.72 \%)$ & $0(0.00 \%)$ & $23(4.89 \%)$ \\
\hline The dysplastic pulmonary valve & LA8A.OY & $2(0.22 \%)$ & $1(0.76 \%)$ & $1(0.21 \%)$ \\
\hline Anomalous origin of the pulmonary artery from aortic artery & LA8A.Y & $1(0.11 \%)$ & $1(0.76 \%)$ & $0(0.00 \%)$ \\
\hline Congenital pulmonary atresia & LA8A.1 & $5(0.54 \%)$ & $4(3.03 \%)$ & $1(0.21 \%)$ \\
\hline Congenital aortic regurgitation & LA8A. 21 & $2(0.22 \%)$ & $0(0.00 \%)$ & $1(0.21 \%)$ \\
\hline Bicuspid aortic valve & LA8A.22 & $1(0.11 \%)$ & $0(0.00 \%)$ & $1(0.21 \%)$ \\
\hline Coarctation of aorta & LA8B.21 & $23(2.48 \%)$ & $1(0.76 \%)$ & $22(4.68 \%)$ \\
\hline Interrupted aortic arch & LA8B.22 & $2(0.22 \%)$ & $2(1.52 \%)$ & $0(0.00 \%)$ \\
\hline Vascular ring & LA8B.2Y & $79(8.53 \%)$ & $5(3.79 \%)$ & $79(16.81 \%)$ \\
\hline Congenital anomaly of great arteries including arterial duct, unspecified & LA8B.Z & $6(0.65 \%)$ & $0(0.00 \%)$ & $0(0.00 \%)$ \\
\hline Congenital coronary arterial fistula & LA8C.2 & $3(0.32 \%)$ & $0(0.00 \%)$ & $3(0.64 \%)$ \\
\hline Divided left atrium & LA8G.0 & $1(0.11 \%)$ & $1(0.76 \%)$ & $0(0.00 \%)$ \\
\hline Atrial septal defect & LA8E.1 & $4(0.43 \%)$ & $2(1.52 \%)$ & $4(0.85 \%)$ \\
\hline Multiple structural developmental anomaly of heart or great vessels & LA8Y & $32(3.46 \%)$ & $27(20.45 \%)$ & $6(1.28 \%)$ \\
\hline Left ventricular cyst & LA8Y & $0(0.00 \%)$ & $0(0.00 \%)$ & $1(0.21 \%)$ \\
\hline Structural developmental anomaly of heart or great vessels, unspecified & LA8Z & 29(3.13\%) & 10(7.58\%) & $0(0.00 \%)$ \\
\hline Total & LA80-LA8Z & $926(100.00 \%)$ & 132(100.00\%) & 470(100.00\%) \\
\hline
\end{tabular}

with birth defects, family history of birth defects and $\mathrm{CHD}$, and history of folic acid intake were significantly related to CHD. Figure 4 summarizes the results of multivariable analysis, which showed that living in countryside (OR: 0.771; 95\%CI: 0.628-0.946), having a childbearing history (OR: 0.802; 95\%CI: 0.676-0.951), twin pregnancy (OR: 1.957, 95\% CI: 1.245-3.076), illness in the first trimester (OR: 1.306; 95\% CI: 1.048-1.628), family history of CHD (OR: 7.156; 95\% CI: 3.29315.552), and having a child with birth defects (OR: 2.086; 95\% CI: 1.167-3.731) were independently associated with CHD.

Model selection was conducted to guarantee robust results. As shown in Additional files 1 and 2, the logistic regression analysis was performed by excluding some uncertain data to quantify the association between these significant factors detected by univariate analysis and CHD.

\section{Discussion}

Previous studies from different areas in China have reported various incidences of $\mathrm{CHD}$, which ranged from 6.87 to 76.00 per 1000 children [6, 17-22]. Compared with previous studies, our study could evaluate the incidence of CHD more accurately. It revealed that the incidence of CHD in the neonatal stage is close to existing research results, and that the positive rate of prenatal CHD screening is higher than that of the incidence of 


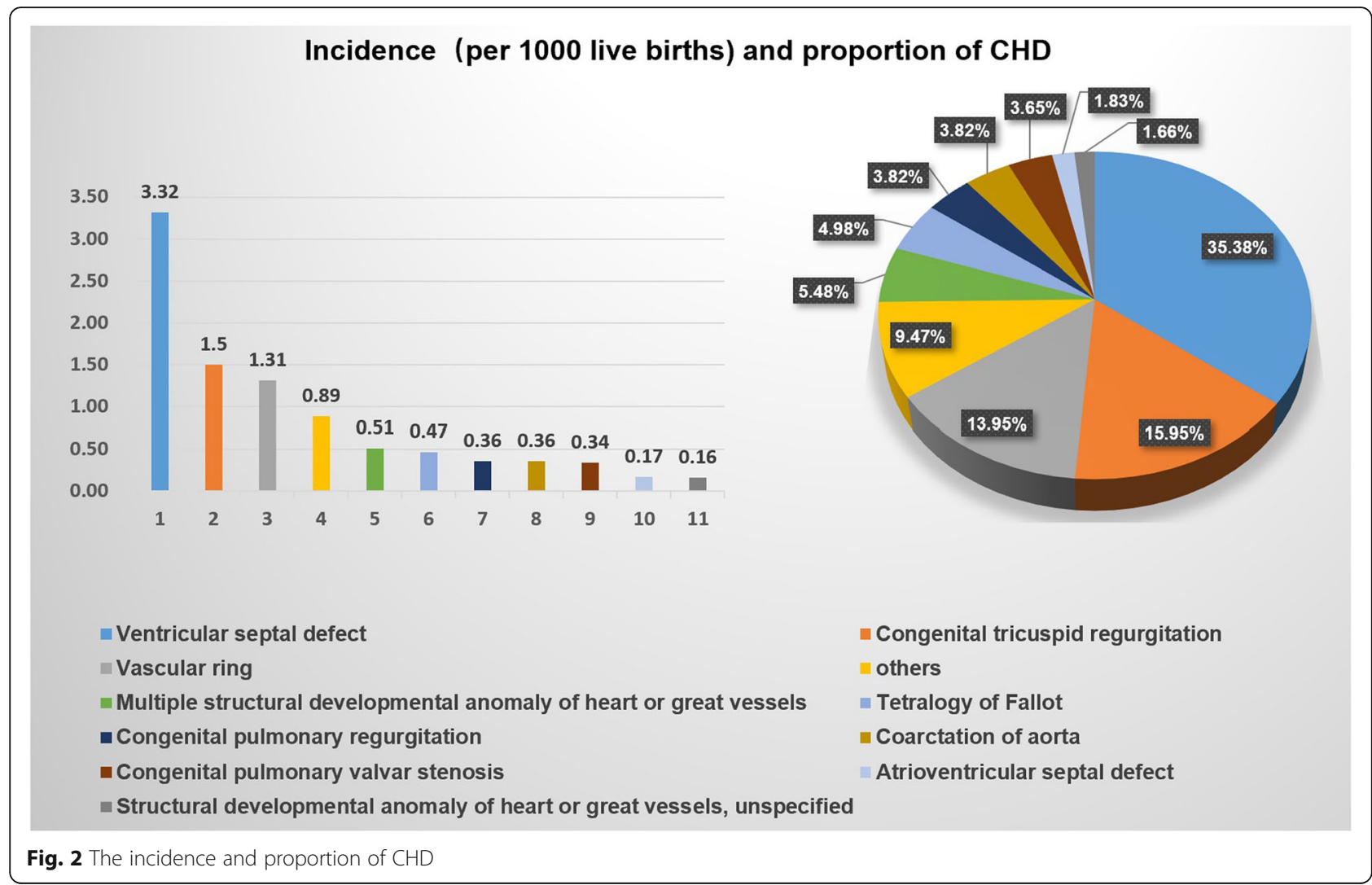

Table 3 Proportion of misdiagnosed and missed cases of CHD

\begin{tabular}{|c|c|c|c|}
\hline Congenital heart disease & ICD-11 code & $\begin{array}{l}\text { no CHD after delivery } \\
\text { (Prenatal screening } \\
\text { with heart abnormalities) } \\
\text { n (\%) }\end{array}$ & $\begin{array}{l}\text { CHD after delivery } \\
\text { (prenatal screening } \\
\text { without heart } \\
\text { abnormalities) n (\%) }\end{array}$ \\
\hline Common arterial trunk & LA85.4 & $0(0.00 \%)$ & $1(2.70 \%)$ \\
\hline $\begin{array}{l}\text { Partial anomalous pulmonary venous } \\
\text { connection }\end{array}$ & LA86.21 & $0(0.00 \%)$ & $1(2.70 \%)$ \\
\hline Congenital tricuspid regurgitation & LA87.00 & 199(62.78\%) & $2(5.41 \%)$ \\
\hline Congenital mitral regurgitation & LA87.10 & $5(1.58 \%)$ & $0(0.00 \%)$ \\
\hline Atrioventricular septal defect & LA87.20 & $1(0.32 \%)$ & $1(2.70 \%)$ \\
\hline Tetralogy of Fallot & LA88.2 & $0(0.00 \%)$ & $1(2.70 \%)$ \\
\hline Ventricular septal defect & LA88.4 & $73(23.03 \%)$ & $20(54.05 \%)$ \\
\hline Hypoplastic left heart syndrome & LA89.3 & $0(0.00 \%)$ & $1(2.70 \%)$ \\
\hline Congenital pulmonary valvar stenosis & LA8A.00 & $3(0.95 \%)$ & $1(2.70 \%)$ \\
\hline Congenital pulmonary regurgitation & LA8A.01 & $30(9.46 \%)$ & $0(0.00 \%)$ \\
\hline Congenital aortic regurgitation & LA8A.21 & $1(0.32 \%)$ & $0(0.00 \%)$ \\
\hline Vascular ring & LA8B.2Y & $0(0.00 \%)$ & $5(13.51 \%)$ \\
\hline $\begin{array}{l}\text { Congenital anomaly of great arteries } \\
\text { including arterial duct, unspecified }\end{array}$ & LA8B.Z & $5(1.58 \%)$ & $0(0.00 \%)$ \\
\hline Atrial septal defect & LA8E & $0(0.00 \%)$ & $2(5.41 \%)$ \\
\hline $\begin{array}{l}\text { Multiple structural developmental } \\
\text { anomaly of heart or great vessels }\end{array}$ & LA8Y & $0(0.00 \%)$ & $1(2.70 \%)$ \\
\hline Left ventricular cyst & LA8Y & $0(0.00 \%)$ & $1(2.70 \%)$ \\
\hline Total & & $317(100.00 \%)$ & $37(100.00 \%)$ \\
\hline
\end{tabular}




\begin{tabular}{|c|c|c|c|c|}
\hline Factors & Level & OR95\%Cl & & Pvalue \\
\hline Twin pregnancy & Yes v.s. No & $1.878(1.198-2.944)$ & $\because$ & 0.006 \\
\hline maternal age & $\geq 35$ v.s. $<35$ & $0.960(.784-1.175)$ & & 0.692 \\
\hline \multirow[t]{2}{*}{ BMI } & $18.5-24.9$ v.s. $<18.5$ & $0.837(.637-1.099)$ & & 0.200 \\
\hline & $\geq 25$ v.s. $<18.5$ & $0.802(.585-1.100)$ & & 0.171 \\
\hline Live location & Countryside v.s. City & $0.742(.605-0.909)$ & & 0.004 \\
\hline Assisted reproduction & Yes v.s. No & $1.713(.984-2.983)$ & ـ & 0.057 \\
\hline \multirow[t]{2}{*}{ Maternal educational level } & medium v.s. low & $1.312(1.046-1.647)$ & . & 0.019 \\
\hline & high v.s. low & $1.849(1.284-2.661)$ & - & 0.001 \\
\hline \multirow[t]{2}{*}{ dietary patterns } & eat less vegetables v.s. well-balanced diet & $0.965(.738-1.262)$ & & 0.797 \\
\hline & eat less meat v.s. well-balanced diet & $1.051(.655-1.687)$ & - & 0.837 \\
\hline Husband's age & $\geq 35$ v.s. $<35$ & $0.849(.702-1.026)$ & & 0.089 \\
\hline \multirow[t]{2}{*}{ Number of previous pregnancies } & 1 v.s. 0 & $0.925(.758-1.129)$ & & 0.443 \\
\hline & $>1$ v.s. 0 & $0.785(.633-0.972)$ & & 0.026 \\
\hline Fertility history & $\geq 1$ v.s. 0 & $0.776(.656-0.920)$ & & 0.003 \\
\hline History of having a child with birth defect & Yes v.s. No & $2.080(1.167-3.707)$ & . & 0.013 \\
\hline History of illness in the first trimester & Yes v.s. No & $1.343(1.077-1.673)$ & 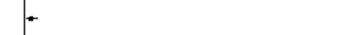 & 0.009 \\
\hline Family history of birth defects & Yes v.s. No & $2.639(1.401-4.973)$ & - & 0.003 \\
\hline Family history of $\mathrm{CHD}$ & Yes v.s. No & $7.791(3.596-16.879)$ & & $<0.001$ \\
\hline \multirow[t]{2}{*}{ Folic acid intake } & $\begin{array}{l}\text { Eating folic acid } 3 \text { months before or after } \\
\text { pregnancy v.s. Does not eat folic acid }\end{array}$ & $1.580(1.016-2.457)$ & - & 0.042 \\
\hline & $\begin{array}{l}\text { Eating folic acid } 6 \text { months before and after } \\
\text { pregnancyv.s. Does not eat folic acid }\end{array}$ & $1.794(1.137-2.833)$ & $\rightarrow$ & 0.012 \\
\hline \multirow[t]{3}{*}{ History of husband smoking before pregnancy } & $<10$ v.s. 0 & $0.781(.617-0.989)$ & & 0.040 \\
\hline & $10-19$ v.s. 0 & $0.925(.712-1.200)$ & & 0.556 \\
\hline & $\geq 20$ v.s. 0 & $0.820(.605-1.227)$ & $\operatorname{l}_{0.5152535455565758595105}$ & 0.408 \\
\hline
\end{tabular}

Fig. 3 Results of univariate logistic regression analysis

CHD in newborns. The main reasons are as follows: a high incidence of tricuspid regurgitation identified prenatally was likely to be a significant overestimate of true cardiac pathology, because at lesser levels this often reflects obstetric/placental /extra-cardiac fetal abnormality; pregnancies with complex $\mathrm{CHD}$ and some with mild CHD select termination; CHD is frequently misdiagnosed in the prenatal screening stage; and there were the cases we missed for the early clinical screening of neonates for CHD.

Our findings provided some important implications for CHD control and prevention. CHD is classified as simple, moderate and complex. As previous studies suggested, the variation in CHD incidence was attributed to minor CHD, but severe CHD remained stable [2].
Termination is not recommended for pregnant women with minor or mild fetal cardiac abnormality. Fetuses who were identified as CHD cases in the fetal stage can have a chance to improve their health with the development of tissues and organs to become a healthy newborn. A majority of the positive cases screened in the fetal stage, such as congenital tricuspid regurgitation and ventricular septal defects, are likely to be repaired by the time the baby is born. In prenatal screening, the false negative rate of prenatal screening was $6.15 \%$. Ventricular septal defects were likely to be missed in the screening. However, this value might be overestimated, because these cases of ventricular septal defect were in the range of $3 \mathrm{~mm}$, and they might be repaired in utero. Abortion and stillbirth should be of extreme concern for

\begin{tabular}{lcc|cc}
\hline Factors & Level & OR95\%Cl \\
\hline Twin pregnancy & Yes v.s. No & $1.957(1.245-3.076)$ \\
Live location & Countryside v.s. City & $0.771(0.628-0.946)$ \\
Fertility history & $\geq 1$ v.s. 0 & $0.802(0.676-0.951)$ \\
History of having a child with birth defects & Yes v.s. No & $2.086(1.167-3.731)$ \\
History of illness in the first trimester & Yes v.s. No & $1.306(1.048-1.628)$ & 0.004 \\
Family history of CHD & Yes v.s. No & $7.156(3.293-15.552)$ & 0.013 \\
& & & 0.0113 \\
\hline
\end{tabular}

Fig. 4 Results of multivariable logistic regression model 
critical CHD fetuses. Most pregnant women and families in China lack knowledge of CHD and eventually choose to terminate with a resulting severe psychological burden. Several induction cases such as small ventricular septal defects could be effectively cured by surgery after birth, and they do not affect quality of life.

The risk factors associated with CHD were identified by the univariate, multivariable analyses. Results from the logistic regression model revealed that having a childbearing history and living in the countryside were negatively associated with $\mathrm{CHD}$ incidence, which may decrease the risk of CHD. In addition, a family history of CHD, history of illness in the first trimester, twin pregnancy, and history of having a child with birth defects before the current pregnancy were positively associated with CHD incidence, which may increase the risk of CHD. These results were mostly similar to those in previous studies [23-26]. Previous studies have pointed out that maternal education level is an independent factor affecting congenital heart disease [27, 28], but our study found that maternal education level and congenital heart disease have no significant correlation. Previous studies had shown that maternal folic acid supplementation is associated with a lower risk of congenital heart defects $[29,30]$. In contrast, the results of our study showed no significant association between folic acid supplementation and CHD risks. This difference might be limited by the roughness of big data. We are collecting more comprehensive information about folic acid and analyzing the results.

There are several limitations in this study. First, several factors such as history of illness in the first trimester and dietary patterns were only summarized or subjective variables. In our study, all of these diseases were summarized as one variable aiming to assess the association between the health status of pregnant women and CHD, rather than between specific diseases and CHD. Moreover, according to this goal and design, there was no more information about the diseases obtained from enrolled pregnant women. In future research, we plan to obtain more detailed information on diseases to detect their association with CHD. The variable of dietary patterns was subjectively described by investigated pregnant women with no quantitative standard. As for the specific association between CHD and eating meat or vegetables and diseases, more information should be obtained in the future to evaluate their effect. Household income was an important variable to evaluate the association between socioeconomic level of the study population and CHD. We should increase the collection of household income information in the dataset. Through prenatal echocardiography and other examinations, we cannot determine whether fetal tricuspid regurgitation was caused by obstetric/ placental/ extra-cardiac fetal abnormality, which might overestimate the true cardiac pathology. CHD is possibly missed in the neonatal screening stage. In addition, missing data were inevitable in a large prospective census-based study, which may influence the accuracy of results. The missing data of each variable were removed for both univariate and multivariable analysis. Considering the large size of the enrolled the pregnant cohort (a total of 64,763women), there was still enough data to ensure that we obtained relatively precise results.

\section{Conclusions}

CHD is a serious health problem in Qingdao. The CHD incidence found in this study was similar to existing research. The positive rate of prenatal CHD screening was higher than the incidence of neonatal CHD. Moreover, CHD risk factors were identified in our study, and our findings may have great implications for formation $\mathrm{CHD}$ intervention strategies.

\section{Abbreviations}

CHD: Congenital heart disease; OR: Odds ratio; MRA: Magnetic resonance angiography; VSD: Ventricular septal defect; Cl: Confidence interval; QMCBDCP: Qingdao Municipal Center for Birth Defect Control and Prevention; QWCH: Qingdao Women and Children's Hospital; BMI: Body mass index; SD: Standard deviation; IQR: Interquartile range; NSFC: The National Natural Science Foundation of China

\section{Supplementary Information}

The online version contains supplementary material available at https://doi. org/10.1186/s12889-021-11034-x.

Additional file 1. Questionnaire.

Additional file 2: Table $1 \mathbf{S 1}$. The results of multivariable regression analysis with the significant risk factors selected by univariate analysis. Table 2 S2. The results of multivariable regression analysis excluding the variable of number of previous pregnancies. Table $\mathbf{3} \mathbf{S 3}$. The results of multivariable regression analysis excluding the variable of family history of birth defects.

Acknowledgements

We are deeply thankful to all workers involved in data collection and diagnosis of fetuses in Qingdao.

\section{Authors' contributions}

Q-SX designed the study and conceptualised the paper. XJ, WN, G-LW, QW, $J Z, G-J L, N J, W J C, Q L$ and LG collected the epidemiological and clinical data. $\mathrm{XJ}$ and WN summarised the data and conducted statistical analysis. XJ and WN wrote the initial draft of the manuscript. All authors provided critical feedback and approved the final version. The corresponding author has full access to all data in this study and attests that all listed authors meet authorship criteria and that no others meeting the criteria have been omitted. The author(s) read and approved the final manuscript.

\section{Funding}

This work was supported by The National Natural Science Foundation of China (NSFC) [Grant number 81770315 and 82071583]; and Taishan Scholars Program. The funders were not involved in the research. All aspects of the study including the research design and interpretation of findings is the responsibility of the author and not the funder. 


\section{Availability of data and materials}

The datasets generated and/or analyzed during the current study are not publicly available due to the restrictions of the local ethics committee and institutional data security and privacy policies. The data access request needs institutional and ethics committee's approval.

\section{Declarations}

\section{Ethics approval and consent to participate}

This study was approved by the Ethics Commission of Qingdao Women and Children's Hospital (QFFLL-KY-2020-11) and written informed consent was obtained from involved patients prior to enrollment.

\section{Consent for publication}

Not applicable.

\section{Competing interests}

The author declares to have no competing interests.

\section{Author details}

${ }^{1}$ Qingdao University, Qingdao, Shandong Province, China. ${ }^{2}$ Qingdao Women and Children's Hospital, Qingdao University, Qingdao, Shandong Province, No.6 Tongfu Road, Qingdao 266000, China. ${ }^{3}$ Qingdao Maternal and Child Health Care and Family Planning Service Center, Qingdao University, Qingdao, Shandong Province, China.

Received: 7 September 2020 Accepted: 11 May 2021

Published online: 02 June 2021

\section{References}

1. Qiang S. Cardiothoracic surgery. In: Ning S, Shan Z, editors. Pediatric surgery (in Chinese). China: People's medical publishing house; 2015. p. 541-604.

2. Hoffman Jl, Kaplan S. The incidence of congenital heart disease. J Am Coll Cardiol. 2002;39(12):1890-900. https://doi.org/10.1016/S0735-1097(02)01886-7.

3. van der Linde D, Konings EE, Slager MA, Witsenburg M, Helbing WA, Takkenberg JJ, et al. Birth prevalence of congenital heart disease worldwide: a systematic review and meta-analysis. J Am Coll Cardiol. 2011;58(21):22417. https://doi.org/10.1016/j.jacc.2011.08.025.

4. Liu Y, Chen S, Zühlke L, Black GC, Choy M-k, Li N, et al. Global birth prevalence of congenital heart defects 1970-2017: updated systematic review and meta-analysis of 260 studies. Int J Epidemiol. 2019. https://doi. org/10.1093/ije/dyz009.

5. Zhao Q-M, Liu F, Wu L, Ma X-J, Niu C, Huang G-Y. Prevalence of congenital heart disease at live birth in China. J Pediatr. 2019;204:53-8. https://doi.org/1 0.1016/j.jpeds.2018.08.040.

6. Hanaoka T, Tamura N, Ito K, Sasaki S, Araki A, Ikeno T, et al. Prevalence and risk of birth defects observed in a prospective cohort study: the Hokkaido study on environment and children's health. J Epidemiol. 2018;28(3):125-32. https://doi.org/10.2188/jea.JE20160108.

7. Gelb BD, Chung WK. Complex genetics and the etiology of human congenital heart disease. Csh Perspect Med. 2014. https://doi.org/10.1101/ cshperspect.a0139539.

8. Liu S, Liu J, Tang J, Ji J, Chen J, Liu C. Environmental risk factors for congenital heart disease in the Shandong peninsula, China: a hospital-based case-control study. J Epidemiol. 2009;19(3):122-30. https://doi.org/10.2188/ jea.JE20080039.

9. Tania M, Amitoz M, Paul V, Cheryl H-G, Heather LB. Prevalence of congenital cardiovascular malformations varies by race and ethnicity. Int J Cardiol. 2010;143(3):317-22. https://doi.org/10.1016/j.jijcard.2009.03.054.

10. Mir A, Jan M, Ali I, Ahmed K, Radhakrishnan S. Congenital heart disease in neonates: their clinical profile, diagnosis, and their immediate outcome; 2019. https://doi.org/10.4103/heartindia.heartindia_3_19.

11. Prakash A, Torres AJ, Printz BF, Prince MR, Nielsen JC. Usefulness of magnetic resonance angiography in the evaluation of complex congenital heart disease in newborns and infants. Dig World Core Med J. 2007;100(4): 715-21. https://doi.org/10.1016/j.amjcard.2007.03.090.

12. Donofrio MT, Moon-Grady AJ, Hornberger LK, Copel JA, Sklansky MS, Abuhamad A, et al. Diagnosis and treatment of fetal cardiac disease: a scientific statement from the American Heart Association. Circulation. 2014. https://doi.org/10.1161/01.cir.0000437597.44550.5d.
13. Wong KK, Fournier A, Fruitman DS, Graves L, Human DG, Narvey M, et al. Canadian Cardiovascular Society/Canadian Pediatric Cardiology Association position statement on pulse oximetry screening in newborns to enhance detection of critical congenital heart disease. Can J Cardiol. 2017;33(2):199208. https://doi.org/10.1016/j.cjca.2016.10.006.

14. Hiatt PW, Mahony L, Tepper RS. Oxygen desaturation during sleep in infants and young children with congenital heart disease. J Pediatr. 1992;121(2): 226-32. https://doi.org/10.1016/s0022-3476(05)81193-x.

15. Reddy VK, Holzman IR, Wedgwood JF. Pulse oximetry saturations in the first 6 hours of life in normal term infants. Clin Pediatr. 1999;38(2):87-92. https:// doi.org/10.1177/000992289903800204.

16. Usen S, Weber M, Mulholland K, Jaffar S, Oparaugo A, Omosigho C, et al. Clinical predictors of hypoxaemia in Gambian children with acute lower respiratory tract infection: prospective cohort study. BMJ. 1999;318(7176):8691. https://doi.org/10.1136/bmj.318.7176.86.

17. Liu WT, Ning SB, Hua BJ, Chen YT, Zhou SY, Guo AL, et al. The incidence and characteristics of children's congenital heart disease in Yangpu and Xuhui districts of Shanghai (in Chinese). Chin J Pediatr. 1995;26(6):832-5. https://doi.org/10.1007/s00246-005-0981-9.

18. Qu Y, Liu X, Zhuang J, Chen G, Mai J, Guo X, et al. Incidence of congenital heart disease: the 9-year experience of the Guangdong registry of congenital heart disease, China. PLoS One. 2016;11(7):e0159257. https://doi. org/10.1371/journal.pone.0159257.

19. Yang M, Zhang S, Du Y. Epidemiology characteristics of birth defects in Shenzhen city during 2003 to 2009, China. J Matern Fetal Neonatal Med. 2015;28(7):799-803. https://doi.org/10.3109/14767058.2014.932767.

20. Wu MH, Chen HC, Lu CW, Wang JK, Huang SC, Huang SK, et al. Prevalence of congenital heart disease at live birth in Taiwan. J Pediatr. 2010. https:// doi.org/10.1016/j.jpeds.2009.11.062.

21. Sun PF, Ding GC, Zhang MY, He SN, Gao Y, Wang JH, et al. Prevalence of congenital heart disease among infants from 2012 to 2014 in Langfang, China. Chin Med J. 2017. https://doi.org/10.4103/0366-6999.204923.

22. Pei L, Kang Y, Zhao Y, Yan H. Prevalence and risk factors of congenital heart defects among live births: a population-based cross-sectional survey in Shaanxi province, Northwestern China. BMC Pediatr. 2017;17(1):18. https:// doi.org/10.1186/s12887-017-0784-1.

23. Yokouchi-Konishi T, Yoshimatsu J, Sawada M, Shionoiri T, Nakanishi A, Horiuchi C, et al. Recurrent congenital heart diseases among neonates born to mothers with congenital heart diseases. Pediatr Cardiol. 2019;40(4):86570. https://doi.org/10.1007/s00246-019-02083-6.

24. Carmichael SL, Nelson V, Shaw GM, Wasserman CR, Croen LA. Socio-economic status and risk of conotruncal heart defects and orofacial clefts. Paediatr Perinat Epidemiol. 2003. https://doi.org/10.1046/j.1365-3016.2003.00498.x

25. Liu SW, Liu JX, Tang J, Ji JF, Chen JW, Liu CY, et al. Environmental risk factors for congenital heart disease in the Shandong Peninsula, China: a hospital-based case-control study. J Epidemiol. 2009;19(3):122-30. https:// doi.org/10.2188/jea.JE20080039.

26. Gianicolo EAL, Mangia C, Cervino M, Bruni A, Andreassi MG, Latini G. Congenital anomalies among live births in a high environmental risk area - a case-control study in Brindisi (southern Italy). Environ Res. 2014;128: 9-14. https://doi.org/10.1016/j.envres.2013.11.002.

27. Liang $Q$, Gong W, Zheng D, Zhong R, Wen Y, Wang X. The influence of maternal exposure history to virus and medicine during pregnancy on congenital heart defects of fetus. Environ Sci Pollut R. 2017;24(6):5628-32. https://doi.org/10.1007/s11356-016-8198-4.

28. Best $K$, Rankin J. Increased risk of congenital heart disease in twins in the North of England between 1998 and 2010. Heart. 2015;101(22):1812. https:// doi.org/10.1136/heartjnl-2015-307826.

29. Ionescu-Ittu R, Marelli AJ, Mackie AS, Pilote L. Prevalence of severe congenital heart disease after folic acid fortification of grain products: time trend analysis in Quebec, Canada. Bmj. 2009;338(may12 2):b1673. https:// doi.org/10.1136/bmj.b1673.

30. van Beynum IM, Kapusta L, Bakker MK, den Heijer M, Blom HJ, de Walle HE. Protective effect of periconceptional folic acid supplements on the risk of congenital heart defects: a registry-based case-control study in the northern Netherlands. Eur Heart J. 2010;31(4):464-71. https://doi.org/10.1 093/eurheartj/ehp479.

\section{Publisher's Note}

Springer Nature remains neutral with regard to jurisdictional claims in published maps and institutional affiliations. 